\title{
A Sociological Analysis of What Counts as Knowledge for Board of Governors of Government Assisted Second Cycle Educational Institutions in Ghana
}

\author{
William Boateng \\ Department of Sociology, University of Saskatchewan 1019 - 9 Campus Drive, Saskatoon SK. S7N 5A5, Canada
}

\begin{abstract}
Boards of governors of second cycle schools in Ghana are mandated to make critical decisions in ensuring effective running of schools. This mandate cannot be well executed without effective knowledge management strategy in place to inform boards' decision-making. Such a strategy should be commensurate with the dominant form of knowledge in use by the board members. Understanding what counts as knowledge in informing boards' decisions is therefore an important prerequisite in designing and institutionalizing a feasible strategy to support knowledge use.

This study involved four conveniently sampled secondary school boards. Qualitative interviews and unobtrusive method involving content analysis of boards' documents were the mixed methodologies for the study. Explicit form of knowledge is the main form of knowledge informing boards' decision-making. Such knowledge/inputs are provided by the heads of the secondary schools. The over reliance on heads of institutions for inputs in boards' decisions raises a concern with regards to the autonomy of the boards as an advisory and supervisory entity. It is recommended among others that board members put in place an explicit policy on knowledge management to enable them harness knowledge/inputs from multiple sources to supplement the inputs from the heads of institutions.
\end{abstract}

Keywords Knowledge, Knowledge Management, Educational Boards, Decision-Making, Secondary Schools

\section{Introduction}

In contemporary knowledge-based society, knowledge management is critical for effective evidence-based decision-making. How organizations manage knowledge is therefore an indispensable precursor for organizational success. Knowledge management is defined as the process by which an organization creates, captures, acquires, validates and uses knowledge to support and improve its overall functioning ([1],[2],[3]).

In this paper, the knowledge management practices and strategies in use by the board of governors of secondary schools in Ghana are explored. The motivation for the paper emanates from a recent revelation that educational decision-makers in Ghana have been struggling to access up-to-date knowledge in informing their decisions[4]. One way of addressing the dearth of up-to-date relevant knowledge in informing decisions is to thoroughly understand the knowledge management practices and strategies presently in use by the board of governors of secondary schools. This is an important step towards the

* Corresponding author:

wib980@mail.usask.ca (William Boateng)

Published online at http://journal.sapub.org/sociology

Copyright (C) 2012 Scientific \& Academic Publishing. All Rights Reserved institutionalization of knowledge management strategies in aid of decision-making within the educational sector.

Generally, secondary education lies between basic education and higher education. Secondary education is a step for pupils between the ages of about 11 or 12 and 18 . At this level, pupils are expected to broaden their knowledge and experiences from the basic level and prepare for work or higher education. Secondary educational institutions are governed by administrative set up by the ministry of education comprising heads of these institutions. These heads work in league with local management structures such as the school's board of governors and the PTAs. Each of these bodies can have a significant impact on the quality of education offered to students and how the schools are governed. This paper will focus on the activities and functions of the schools boards who are appointed and may not necessarily have credentials in education, yet are expected to play a lead role in the governance of these secondary schools. The central focus of the discussion will be placed on what counts as knowledge in informing the boards' decision-making. This is critical in designing a knowledge management strategies geared towards the maximization of the benefits associated with the use of the knowledge form(s).

Effective decision-making in an information age implies the use of scientific knowledge. Decision-making itself, 
however, is a complex activity, and it is often difficult, if not impossible, to attribute any particular decision to the specific use of scientific knowledge. The relationship between scientific knowledge and decision-making is, therefore, often indirect and varied[5]. Typically, scientific knowledge must compete with other forms of knowledge - e.g. popular understandings, value based judgments, political imperatives - and the attraction of the status quo. This is no less true for secondary schools decision making, and the extent to which scientific evidence combines with other forms of knowledge in this context needs to be examined.

In the context of secondary schools decision-making, there has been little attention paid to studies that investigate the role of knowledge management in these processes. Since knowledge is an important input to successful decision making, it is necessary for educational decision makers to pay greater attention to its management. This paper aims to better understand the role of knowledge management in secondary schools. This is an important step towards improving the delivery of secondary education.

The fact that effective management of knowledge plays an important role in overall organizational success is supported by the success of knowledge management strategies and practices in the business sector. Other sectors of the economy and society, including education, would arguably stand to benefit from a similar emphasis and engagement in knowledge management strategies and practices. Since educational decision-makers use a variety of knowledge to inform their decisions, it is imperative that they effectively manage the knowledge they have at their disposal. In order to ensure effective decision making, a more thorough understanding of knowledge management is required.

Specifically, however, the following objectives guided the study: to identify the main types of knowledge used for boards' decision-making; to identify the primary knowledge management strategies of board members; and to identify the knowledge management practices adopted by board members to support their decision-making processes.

\section{Levels of Educational Decision-Making}

The Ghana's educational system is confronted with the task of effectively managing the resources necessary for improving teaching and learning in schools. Fulfilling this task successfully implies sound and effective decision making at critical points throughout the entire system. Decision-making in contemporary Ghana's educational system takes place at the macro-, meso-, and micro-levels. Each of these levels has a distinct mandate, but all are linked in contributing to overall improved quality education.

Macro-level decisions in the secondary schools involve the overall planning, organizing, delivery and evaluation of educational services in the country. This decisions are made by the board members appointed by the sector minister for education. The mandate of the boards is to oversee the functions and operations of the various secondary schools in the country. The secondary school boards are mandated to ensure effective governance and administration of secondary schools in the country. Ultimate decisions made in ensuring effective school governance and administration are endorsed by the board members at the macro-level. Clearly, board members make critical decisions on behalf of the Ministry of Education. Board members rely on technical expertise of the Heads of the schools and their management teams.

Administrative decisions and priorities are made by the Heads and their management teams in collaboration with local stakeholder groups at the meso-level of the educational decision-making process. Decisions made at this level have to be endorsed at the macro-level by the board members. The fact that board members normally do not initiate but rather endorse administrative decisions has given a dual connotation of their role. On one hand, they are perceived as advisors. On the other hand they come across as decision-makers. Officially, board members have the mandate to validate all decisions made within a school, thus making them important players in the overall educational decision-making process.

The third level of educational decision-making takes place at the micro-level. Decisions at this level are made by individual teachers and other supporting and technical staff commonly referred to as frontline staff. Decisions made at each level can influence the other levels. Micro level decisions, for example, are influenced broadly by the macro level, though this is often restricted to budget-based resource allocation and monitoring; there is no direct relationship between decision-makers at the macro and the micro levels. Meso-level educational decision-makers, however, exercise tremendous influence on decisions made at the micro level. Educational targets to be attained by teachers and resources to be used for that purpose are determined by the meso-level decision-makers upon approval from the macro-level decision-makers.

\section{Board of Governors as Decentralized Entity}

The introduction of the secondary school board concept came to being in Ghana in the sixties through the Education Act of 1961 (Act 87). This was part of a decentralized program aimed at monitoring and evaluating the activities of the heads of government assisted secondary schools and also to assist them in their administration. The board members are appointed by the Minister of Education and operate based on a constitution drawn by the minister. All secondary school boards are expected to compose of the following members: A representative each from the Ministry of Education, Ghana Education Service, Regional Educational Directorate, and the District Educational Directorate. Other members include a representative each from the Parent and Teachers Association, and the Regional Coordinating Office. Further, two members each are to represent the following bodies - the 
schools' staff, the local communities or historical interest, alumni, and the District Assemblies. The heads of the schools are also automatic members of the boards. All these members are vetted by their respective regional coordinating officers and subjected to criminal checks before final acceptance to the boards[6].

The main function of the boards is to oversee the activities of the heads of the school to ensure effective delivery of education, but doing so in a way not to usurp the powers vested in the heads by the Minister of Education. The boards can be said to be part of a decentralized system aimed at effective governance and social accountability in many developing countries[7]. Not only are the boards perceived as conduit for improved delivery of educational services, but they have also come to stand for a mechanism to improve the democratisation of decision-making for increased system efficiency[8].

The boards now occupy an important macro level decision-making position in the educational sector. This is the case because of the recent push by international development agencies to make decentralised governance a key part of reforms to improve education service delivery in developing countries ([9],[10]). Further, it is argued that decentralized governance can produce greater community pressure for transparency and accountability in school management[11]. In Ghana, for example, educational decentralisation has been presented as the vehicle for strengthening management efficiency and accountability by locating critical decision-making of educational matters at the school boards' level. Further, decentralisation has also been noted as encouraging local actors to mobilise resources to help tackle problems of quality and access to education.

A strong case has been made for decentralized governance in secondary schools. Reference[10] for instance found a strong belief among parents, teachers, local councillors and education officials with regards to the significance of the boards in school governance. Reference[9], however, found that core education decisions are hardly ever decentralised in a way that encourages genuine local community participation in decision-making. The boards' roles have been found to be largely regulatory in nature[11], thus making them to focus more on 'official' responsibilities based on traditional roles, rather than on attempting to redefine their roles in response to peculiar needs[12]. The fact that the boards are composed of about $50 \%$ representatives from the Ministry of Education and its subsidiary agencies might account for the largely regulatory role played by the board members. This deviates from one of the purposes of decentralising education services, which is to widen the participation of non-education professionals at local community level in the running and management of schools[10].

Clearly, the hybrid composition of boards' membership those with, and without, credentials and experience in educational administration - raises the all important question regarding the knowledge base informing their decisions. The literature is emphatic about the dearth of up-to-date knowledge in aid of boards decision-making[4], and also over reliance on the heads of institutions for inputs and directions. Reliance on the heads of institutions for inputs, in itself, is a step in the right direction, but board members should be motivated and resourced well enough to access and utilize alternative sources of knowledge to appraise heads' inputs in order to inform their decisions. A knowledge management strategy, no doubt, is essential to abet board members' decision-making.

\section{The Role of Knowledge Management in Boards' Decision-Making Process}

As said prior, knowledge management is central to organizational success[13]. Unfortunately, the current educational system often lacks the adequate mechanisms for managing the type of information that can effectively inform decision-making[4]. Contemporary educational system generate massive amounts of knowledge and information. This is one of its great strengths. At the same time, this resource is not yet fully leveraged for improving the management and delivery of educational services. Currently, heads of secondary schools are expected to manage and disseminate information and data to mostly lay board members, in a timely, useable form that supports their decision-making. This becomes a concern when this source of knowledge is the sole conduit of knowledge in informing board members' decisions. As a result, this raises a number of questions relating to the management of knowledge by the board members.

Without a doubt, effective strategies for the management of knowledge available to board members will have much to say about the quality of the decisions they make. There is, therefore, the need to step up knowledge/research utilization among board members, particularly in light of studies that show knowledge utilization among board members is somewhat lacking. This is partially attributable to the fact that Ghana, like many other developing countries, continues to have problems with out-of-date and not very reliable data, as well as accessibility to such data[4].

\section{Evidence Based Decision-Making in Education}

Evidence-based decision-making refers to the rigorous use of science or research evidence as the basis for making decisions. Since the early 1990's, various fields of human endeavour, including medicine and health care policy-making, have taken up the challenge of evidence-based practice. This is yet to be prominent in the macro level educational decision-making process. Proponents of evidence-based practice believe that explicit knowledge should be one of the main pillars of decision-making.

The rationale for evidence-based decision-making in education derives strongly from the need for board member 
and school administrators to be more socially and economically accountable to their clients. Board members and school administrators, therefore, need to develop evidence-based practices in order to substantiate and justify their decisions and actions.

Board members may not be in dire need of best evidence from scientific research to inform their decisions, given their role as mainly "non educational experts" charged with the responsibility of planning and overseeing school administrations. At best, board members may be looking for evidence from school administrators, which may be internally generated evidence rather than external scientific evidence to inform their decisions. These decisions are mainly based on the values and priorities of the schools. What constitute best evidence, therefore, may differ from one school to another, depending primarily on the peculiar needs and situations of a school. As a result, a singular understanding of "evidence" in boards' decision-making process may not work. Various school boards should seek the best evidence that advances their primary interests and responsibilities.

Drawing on the general definition of evidence-based decision-making, evidence-based educational decision-making may be defined as the conscientious, explicit, and judicious use of current relevant best evidence in making decisions about educational planning and delivery. Evidence-based educational decision-making, however, should appreciates a wider interpretation of "evidence", including (1) valid, important and applicable students interests, (2) Board members experience, and (3) relevant research-derived evidence.

\section{Forms of Knowledge}

The concepts "knowledge", "data" and "information" are often used interchangeably. Although the meanings of data, information and knowledge overlap, they are distinct. The fundamental difference between these concepts is that while data are conceived of as unorganized facts and observations, information goes beyond by virtue of it being contextualized. Information, therefore, is data placed in context. Knowledge is also information, but such information can be judged to ascertain its truthfulness. Knowledge could be said to be formal when it is based on scientific evidence, whose validity and reliability can be tested over a reasonable period of time. Informal knowledge, differently, is experiential in nature and is acquired after an exemplary practice has been put to use over a period of time. Informal knowledge, unlike formal knowledge, is difficult to replicate since the means for its acquisition are difficult to share[14].

Reference[15] identifies explicit and tacit forms of knowledge as the two forms of knowledge used in organizations. These two forms of knowledge are currently recognized as the de facto knowledge categorization informing decision-making in almost all organizations. Polanyi believes that a large part of human knowledge is tacit.
Knowledge of this type is action-oriented and has a personal quality that makes it difficult to communicate. Accessing tacit knowledge, therefore, presents a number of challenges, due to factors such as the absence of explicit scientifically repeatable process for eliciting such forms of knowledge. Explicit knowledge, however, can be communicated across time and space.

Conceptually, there is a clear distinction between these two forms of knowledge. Nevertheless, they are not discrete or independent in the practical sense. These forms of knowledge are not dichotomous, but mutually dependent and reinforcing ([16],[17]). Fostering a dynamic interaction between tacit and explicit knowledge, therefore, generates new forms of knowledge vital for organizations[18],[17]). Individuals in organizations learn by actively participating in the processes involved in knowledge creation. Through these processes, knowledge is transformed within and between forms usable by people in organizations.

Reference[18] describes the knowledge creation process as a five-step process involving four modes of knowledge conversion. The process starts with the tacit knowledge of one or several individuals, who share it with others, thereby developing a common understanding. This common understanding is transferred into explicit knowledge in the form of a concept in the second step of the process. In the third step that concept is justified by comparing and linking it to other forms of explicit knowledge internal as well as external to the organization. In the fourth step the concept is manifested into a model operating procedure that can be further discussed and tested. In the final step the new knowledge is cross-levelled or spread throughout the organization.

Reference[18] believes that four modes of knowledge conversion are at work. These include socialization (transferring tacit knowledge to tacit knowledge); externalization (transferring tacit to explicit knowledge); combination (explicit to explicit knowledge); and internalization (transferring explicit to tacit knowledge). In this model, tacit knowledge is generally viewed as prerequisite for the use of explicit knowledge. It is through tacit knowledge that explicit knowledge is interpreted and manifested in action. Nonanka and Tekeuchi's knowledge conversion, therefore, implies that tacit knowledge is the basis for knowledge transfer.

Though knowledge conversion has a conceptual value in understanding the complex processes involved in knowledge transfer, the proponents failed to elaborate explicitly how the knowledge conversion processes work empirically. The unilateral sequence for knowledge conversion posited by Nonanka and Tekeuchi is subject to debate because knowledge conversion processes can vary depending on the context in which they occur. Furthermore, the use of the concept "knowledge conversion" in itself makes the understanding of knowledge management processes more mystifying. This observation is made in light of the already existing confusion surrounding the concepts (1) knowledge transfer, which seems to assume knowledge as a product; and 
(2) knowledge translation, which captures knowledge as a process. The introduction of the knowledge conversion concept is a source of confusion because the concept has not been clarified operationally by the proponents.

In spite of these observations, however, it is clear that many researchers in knowledge management are currently testing empirically the knowledge conversion paradigm. It is believed that the verification of the concept empirically over time will ultimately dissipate the current aura of confusion around knowledge management and its related conceptual paradigms.

The literature thus emphasizes two major and complementary forms of knowledge, tacit and explicit. However, an unresolved issue remains. That is the uncertainty surrounding which form of knowledge prerequisites the other. Two lines of arguments emerge here. References ([17],[18]) argue that tacit knowledge serves as a prerequisite for explicit knowledge. A contrary view argues that explicit knowledge precedes tacit knowledge ([19],[20]). Resolving this issue is important, but is itself not essential to enriching knowledge management in organizations. What is essential is an organization's ability to mobilize and integrate the tacit-explicit knowledge forms into a productive knowledge management strategy. Both knowledge forms play a decisive role in the development and management of knowledge in organizations. Organizations draw on both tacit and explicit knowledge forms in making decisions. Identifying the main form of knowledge used in decision-making has implication for institutionalizing knowledge management strategies in organizations.

\section{Knowledge Management Strategies}

Knowledge management in the context of educational boards' decision-making remains under explored. The literature is relatively mute on the main knowledge form as well as various knowledge management strategies used in informing boards' decisions. This needs to be understood in order to identify the conditions that facilitate and/or impede the decision making processes. Again, an understanding of the knowledge management processes in educational boards' decision-making will assist in creating the enabling organizational culture to sustain effective management of knowledge.

Knowledge management can also be understood as the exploitation and development of the knowledge assets within an organization, aimed at furthering the goals and objectives of the organization[21]. Knowledge management, therefore, can be said to involve a conscious effort to incorporate strategies and practices that ensure maximum use of knowledge in organizations with the aim of advancing the goals and objectives of the organization. It is presently recognized that successful organizations are those that create new knowledge, disseminate it widely throughout the organization, and represent it into new technologies and products ([21],[13], [22]). Perceiving knowledge management as a condition of organizational success makes it imperative for organizations to embrace and engage in strategies geared towards its use.

A knowledge management strategy is simply a plan that describes how an organization intends to better manage its knowledge for the benefit of that organization and its stakeholders. A good knowledge management strategy is closely aligned with the organization's overall strategy and objectives. Selecting the right knowledge management strategy is, therefore, an important prerequisite for attaining organizational objectives. Reference[13] points at two contrasting strategies for knowledge management: codification and personalization. They believe that the best knowledge management strategy is always a combination of the two, but with a stronger emphasis on one. While a codification strategy is appropriate for explicit knowledge to thrive, the personalization knowledge management strategy better supports the use of tacit knowledge in organizations[23]. Since tacit and explicit knowledge forms are complementary, an organization's efforts towards knowledge management should be focussed on instituting the most appropriate strategy.

These two knowledge management strategies have distinctive features. The codification knowledge management strategy ensures the re-use of explicit knowledge by capturing, codifying, classifying and making available knowledge to support routine problem solving. This strategy seems to overemphasise internally generated explicit knowledge re-use, without any reference to the use of external explicit knowledge in the form of research evidence. This is a flaw, but since explicit knowledge comes from both internal and external sources, attempts at its management should be comprehensive enough to reflect this duality.

This notwithstanding, the codification knowledge management strategy based mainly on internal explicit knowledge can complement the evidence-based decision-making paradigm, which also seems to be tilted towards externally generated explicit knowledge to the neglect of explicit knowledge generated internally in an organization. Harmonizing the codification knowledge management strategy and the evidence-based decision-making paradigm has the potential to provide a more comprehensive perspective on explicit knowledge management in organizations.

The personalization knowledge management strategy, on the other hand, is suitable for a one-off, medium to long-term, high risk, strategic problem with no solution precedent. This strategy shares tacit knowledge by helping staff to identify experts and enhance conversations to create novel solutions. The forms that solutions to problems might take-and who in the organization might know about the solution - are the primary user questions guiding the personalization knowledge management strategy. Since communication is the bedrock of the personalization strategy, organizations adopting this strategy must reward direct communication 
with others, as well as recognizing experts and original solutions. This strategy of managing knowledge entails a modest investment, justified by improved frequency and quality of communications[13].

Since codification and personalization knowledge management strategies exhibit contrasting features, they should be commensurate with the dominant knowledge form of any given organization. The features of the two knowledge management strategies indicate clearly that organizations embedded with the use of explicit and tacit knowledge forms lend themselves largely to codification and personalization knowledge management respectively.

\section{Methodology}

The study was premised upon the qualitative research design approach. Four secondary schools boards were conveniently sampled for the study. A mixed method approach was utilized in the data collection process of the study. The methods used were qualitative interviews and unobtrusive methodology involving content analysis.

The qualitative interview was directed at the members of the four conveniently selected boards to examine what counted as knowledge in informing their decisions as a board. Further, the unobtrusive methodology involving content analysis was used to study the documents used by board members in informing their decisions. The data from these mixed methods were put together and provided the basis for the study's discussion.

\section{Analysis and Discussion}

The qualitative interviews with the board members clearly portrayed that board members rely mainly on knowledge/inputs from the heads of the institutions in informing their decisions. They were unanimous in expressing this fact. The respondents were further asked whether they did find the inputs from the heads helpful. Most felt that they would do way better if resourced to access other documents to supplement those obtained from the heads. Majority of the respondents were unhappy with the untimely receipt of documents from heads of schools, thus giving them no time to study such documents thoroughly prior to meetings.

A scientific scrutiny into the documentations available to the secondary schools board members makes it clear that members use more explicit rather than tacit knowledge form to inform their decisions. This fact is being expressed against the backdrop that they rely mainly on professional reports received from heads of the secondary schools to guide their discussions at the board's table. Such professional reports include annual school reports, summary of examination results, strategic and development plans.

It must also be noted that achieving effective knowledge management in educational boards' decision-making process involves a combination of many variables such as the school-based structure and culture, and the extent of individual board members interactions ([24],[25]). Important here is the observation that individual board members neither work in isolation, nor are they (usually) able to make wholly autonomous decisions. They work in boards embedded with routines and established cultures, which influence their actions regarding knowledge use in decision-making. Individuals' examples of knowledge utilization, therefore, are greatly shaped by the extent to which they have been socialized into their "communities of practice" through membership on the board as a subculture, and as part of its ongoing learning process. Such informal networks have tremendous impact on decision-making ([26],[27]). Communities of practice manifest themselves in boards cultures, which serve as major motivation to knowledge sharing[16].

Though, school board members may not qualify completely as communities of practice, they may well be said to exhibit some features similar to communities of practice. Such features include the positive relationship that exists among the members, the engagement in team activities, ability to engage in informal tacit knowledge sharing through the use of telephone and emails, and the inter-organizational search for knowledge. These features can be perceived as critical prerequisites for the formation of communities of practice. At best, board members may be described as possessing almost all the fundamental features for the formation of communities of practice. This opportunity, however, has not been exploited to support the management of knowledge by the board members.

\section{Way Forward}

Based on the above discussions, the following recommendations are worth considering in ensuring improved knowledge management in educational boards' decision-making process. For these recommendations to work, they should be supported by the ministry of education and the heads of the schools.

There is the need for school boards to have explicit or official policy on knowledge management. The absence of explicit policy guiding knowledge management negates the benefits associated with these practices. Knowledge management policy is critical in spelling out in clear terms the overall objectives of the boards, the knowledge management strategies and practices to be adopted by its members, and systematically designing ways of ensuring that knowledge management strategies and practices adopted by the boards are commensurate with, and lend credence to the mission of the school boards.

It is evident that board members are indirectly adopting codification knowledge management strategies more than personalization knowledge management strategies. Since codification knowledge management strategies ensure re-use of explicit knowledge by capturing, codifying, classifying 
and making available knowledge to support routine problem solving, the availability of boards members' incentives enshrined in the official knowledge management policy of the boards becomes paramount. This is important because codification knowledge management strategies, unlike personalization strategies, need to be carefully and tactically nurtured to maximize its impact in decision-making.

Efforts at enhancing the use of codified knowledge in boards' decision-making should be directed at broadening the explicit knowledge base of board members to include externally-based relevant research. This will complement the internally-based inputs provided by the heads of the schools. The internally-based evidence placed at the disposal of board members may not be enough evidence in making evidence-based decisions and also over-seeing the activities of the schools. Board members stand to gain a lot from external evidence by learning from experiences of other boards and relevant research. Such an attempt will advance significantly board members' efforts in embracing evidence-based decision-making.

School board members should also be very cautious and tactful in relying mainly on the heads of schools for inputs to inform their decisions. This is important because over-reliance on the heads will amount to erosion of their power as independent advisory body in the educational decision-making process, as enshrined in the act underlying its establishment. Again, heads of schools will be more empowered and unaccountable if given the opportunity to fully steer the directions of board members' activities. Board members should be encouraged and motivated to informally have discussions on management inputs, have them evaluated well in advance of formal board members' meetings, so they become fully represented in decisions made by the boards, rather than becoming a mere rubber-stamp.

Furthermore, since board members also use tacit knowledge in informing their decisions, it is expected that they engage in some knowledge management practices that support personalization strategies. It is a fact that, not everything individuals or a group of people know can be codified as documents or tools for "universal" use. Supporting personalization knowledge management strategies means that an intervention is put in place to facilitate the management of tacit knowledge. One such intervention is the community of practice approach. Even though communities of practice generally emanate voluntarily, they can be deliberately introduced and nurtured in organizations[28]. Cultivating communities of practice among school board members means arrangements such as: formal physical, virtual spaces to facilitate free flow of information among members, and motivate members to belong to such communities are provided.

Through the communities of practice approach, board members can engage in informal discussions to facilitate tacit knowledge sharing to enrich members' decisions. The online rather than face-to-face communities of practice seem to be the best fit for the board members. Though online communities of practice can be costly because they are computer-based, they can support board members' interaction despite their dispersed geographical destinations. Furthermore, since communities of practice can go beyond an organization, online communities for board members can be broadened to incorporate other individuals from the public to share knowledge on school governance. Again the public will also have the opportunity to be part of board members' discussions by participating in such online communities fora. Such a move will indeed make the school governance structure a true democratic entity.

\section{REFERENCES}

[1] Kinney, T., " Knowledge Management, Intellectual Capital and Adult Learning", Adult Learning, 10 (2), pp. 2-5, 1998.

[2] Davenport, T. H., De Long, D. W., and Beers, M. C., "Successful Knowledge Management Projects", Sloan Management Review, 43-57, 1998.

[3] Bhatt, Knowledge Management in Organizations: Examining the Interaction between Technologies, Techniques and People", Journal of Knowledge Management, 5, 1, pp.68-75, 2001.

[4] Wereko, T. B., and Dordunoo, C., " Ghana - Effective Delivery of Public Services: Focus on Education". Discussion Paper, Institute for Democratic Governance, 2010.

[5] Weiss, C. H., "The Many Meanings of Research Utilization", Public Administration Review, 29, 426-431, 1979.

[6] Sekyere, E. A., "Teachers Guide for on Topical Issues for Promotion and Selection Interviews", Afosek Education, 2011.

[7] Litvack J., Ahmad J, and Bird R., "Rethinking Decentralisati on in Developing Countries", The World Bank Sector Studies Series, Washington DC: World Bank, 1998.

[8] Jutting J, Kauffmann, C, McDonnell I, Osterrieder H, Pinaud $\mathrm{N}$, and Wegner L., "Decentralisation and Poverty in Develop ing Countries: Exploring the Impact", OECD, DEV/DOC Working Paper No. 236, 2004.

[9] Naidoo, R.M., "Educational Decentralization in Sub-Saharan Africa - Espoused Theories and Theories in Use", Paper presented at the annual meeting of the Comparative and International Education Society, Orlando, FL, March 6-9, 2002.

[10] De Grauwe, A., Lugaz, C., Baldé, D., Diakhaté, C., Dougnon, D. Moustapha M, and Odushina, D., "Does Decentralization Lead to School Improvement? Findings and Lessons from Research in West Africa", Journal of Education for International Development, 1(1), 2005.

[11] Chapman, D. W., "Trends in Educational Administration in Developing Asia", Educational Administration Quarterly, 36: 283-308, 2000

[12] Tikly, L., "The Role of Local Government in the Provision of Schooling: Experiences from Four Developing Countries", Education Policy Unit (EPU), 1996. 
[13] Hansen, M. T., Nohria, N., and Tierney, T., "What's Your Strategy for Managing Knowledge?", Harvard Business Review, Vol. 77, No. 2, 106-116, 1999.

[14] Connell, N. A. D., Klein, J. H., and Powell, P. L., "Its Tacit Knowledge But Not As We Know It: Redirecting the Search for Knowledge", Journal of the Operational Research Society, 54, pp. 140-152, 2003.

[15] Polanyi, M., "The Study of Man", Chicago: University of Chicago Press, 1964.

[16] Alavi, M., and Leidner, D. E., "Review: Knowledge Management and Knowledge Systems: Conceptual Foundations and Research Issues", MIS Quarterly, 25 (1), pp. 107-136, 2001.

[17] Lam, A., "Alternative Societal Models of Learning and Innovation in the Knowledge Economy", International Social Science Journal, Vo. 54, No. 1, 67-82, 2002.

[18] Nonanka, I., and Takeuchi, H., "The Knowledge Creating Company". New York: Oxford University Press, 1995.

[19] Polanyi, M., "The Tacit Dimension", London: Routledge and Kegan Paul, 1967.

[20] Dreyfus, H., and Dreyfus, S., "Why Computers May Never Think Like People". Technology Review, Vol. 89, No. 1, 42-62, 1988.

[21] Metaxiotis, K., Ergazakis, K., and Psarras, J., "Exploring the World of Knowledge Management: Agreements and
Disagreements in the Academic/Practitioner Community", Journal of Knowledge Management, Vol. 9, No. 2, 16-18, 2005.

[22] Leonard, D., "Wellsprings of Knowledge - Building and Sustaining the Sources of Innovation", Harvard Business School Press, Boston, M. A., 1999.

[23] Jasimuddin, S. M., Klein, J. H., and Connell, C., "The Paradox of Using Tacit and Explicit Knowledge Strategies to Face Dilemmas", Management Decision, Vol. 43, No. 1, 102-112, 2005

[24] Lesser, E. and Prusak, L., "Communities of Practice, Social Capital and Organizational Knowledge", MA: IBM Institute for Knowledge Management, 1, 1999.

[25] Donoghue, L. P., Harris, J. G., and Weitzman, B. A., "Knowledge management strategies that create value", Outlook, 1, pp. 48-53, 1999.

[26] Wenger, E., "Communities of Practice: Learning, Meaning, and Identity", Cambridge University Press, Cambridge, UK, 1998.

[27] Brown, J. S., and Duguid, P., "Knowledge and Organization: A Social-Practice Perspective", Organization Science, 12 (2), 198-213, 2001

[28] Wenger, E., McDermott, R., and Snyder, W. M., "Cultivating Communities of Practice: A Guide to Managing Knowledge", Boston, MA: Harvard Business School Press, 2002. 